\section{INHIBITORS OF DIACYLGLYCEROL KINASE FROM Drechslera sacchari}

\section{Hiroshi Ogawara, K yolchiro Higashi, TOSHIKI Machida, JUNKo TAKASHIMA ${ }^{\dagger}$, Noriko ChiBa ${ }^{\dagger}$ and TAKASHI MIKaWA ${ }^{\dagger}$}

Department of Biochemistry, Meiji College of Pharmacy, Nozawa-1, Setagaya-ku, Tokyo 154, Japan

${ }^{\dagger}$ Research Center, Mitsubishi Kasei Corporation, Kamoshida-cho, Midori-ku, Yokohama 227, Japan

(Received for publication November 24, 1993)

Cells respond to a variety of signals by activation of a phospholipase $\mathrm{C}$ which catalyzes the phosphodiesteric cleavage of phosphatidylinositol 4,5bisphosphate to generate intracellular second messengers, inositol 1,4,5-trisphosphate and 1,2diacylglycerol. Previously, we described the isolation of an inhibitor for inositol-specific phospholipase C from Actinomadura sp. This inhibitor therefore may be a valuable tool for elucidating the mechanism of the signal transduction pathway of various systems as well as a hopeful candidate for cancer chemotherapy ${ }^{1,2)}$. On the other hand, diacylglycerol kinase phosphorylates diacylglycerol to form phosphatidic acid. This enzyme is known to be elevated by extracellular stimuli to accumulate phosphatidic acid by phosphorylating diacylglycerol, and to be involved in the attenuation of protein kinase $\mathrm{C}$ by decreasing the concentration of diacylglycerol in the cells ${ }^{3)}$. However, the detailed function of this enzyme remains to be clarified. Thus, an inhibitor of diacylglycerol kinase would be a useful reagent to explore the role of this enzyme in the signal transduction pathways in various systems and a possible candidate for cancer chemotherapy. This report describes the isolation of D2597 substances from Drechslera sacchari, which are inhibitors of diacylglycerol kinase from bovine thymus.

The microorganism producing the inhibitors was isolated from a fallen leaf sample. Based on the cultural and physiological properties, the producing strain D2597 was identified as Drechslera sacchari.

Diacylglycerol kinase used for the screening was partially purified from bovine thymus by the method of SAKANE et al. ${ }^{4)}$ with a slight modification. Diacyglycerol kinase activity was determined in a final volume of $50 \mu \mathrm{l}$ containing $219 \mu \mathrm{M} 1,2$-dilauroyglycerol $(\mathrm{C} 12: 1), 100 \mu \mathrm{M}\left[\gamma^{32}{ }^{32} \mathrm{P}\right] \mathrm{ATP}(0.5 \sim$ $1.0 \mu \mathrm{Ci}), 50 \mathrm{~mm}$ Tris- $\mathrm{HCl}(\mathrm{pH} 7.5), 50 \mathrm{~mm} \mathrm{NaCl}$,
$0.1 \%$ bovine serum albumin, $0.5 \mathrm{~mm}$ ethyleneglycol bis( $\beta$-aminoethylether)- $N, N, N^{\prime}, N^{\prime}$-tetraacetic acid (EGTA), $5 \mathrm{~mm} \mathrm{MgCl}, 0.04 \%$ sodium deoxycholate, $40 \mathrm{ng}$ partially purified diacylglycerol kinase and with or without the inhibitor. After incubation for 20 minutes at $37^{\circ} \mathrm{C}$, the reaction was terminated by the addition of $500 \mu \mathrm{l}$ of a mixture composed of chloroform, methanol and concentrated $\mathrm{HCl}$ $(200: 100: 1, \mathrm{v} / \mathrm{v} / \mathrm{v})$. Then, $125 \mu \mathrm{l}$ of $1 \mathrm{~N} \mathrm{HCl}$ was added to the mixture, mixed and was centrifuged for 10 seconds at $16,000 \mathrm{rpm}$. The lower phase was collected and concentrated to dryness. The dried solid was dissolved in $10 \mu \mathrm{l}$ of chloroform and the solution was applied to a silica gel thin-layer plate. After development with chloroform, methanol, acetic acid and water $(170: 25: 25: 6, \mathrm{v} / \mathrm{v} / \mathrm{v} / \mathrm{v})$, a spot corresponding to phosphatidic acid was cut out and the radioactivity in this area was measured by a liquid scintillation counter after dissolving in methanol.

Five loopful of cells of the strain D2597 from an agar slant were inoculated into each of 20 bottles of a $200-\mathrm{ml}$ Erlenmeyer flask containing $40 \mathrm{ml}$ of potato - glucose agar. The medium was incubated at $26^{\circ} \mathrm{C}$ for 14 days. The inhibitors were purified as shown in Fig. 1. To each of the bottles $80 \mathrm{ml}$ of $50 \%$ acetone in water were added and the inhibitors were extracted. The acetone solution was concentrated and $500 \mathrm{ml}$ each of water and ethylacetate were added. After the $\mathrm{pH}$ was adjusted to 2.0 with $\mathrm{HCl}$ and the inhibitors were extracted into the ethylacetate layer, the organic solvent layer was concentrated to dryness under reduced pressure to give $400 \mathrm{mg}$ of crude solid. The solid thus obtained was dissolved in a small amount of dichloromethane and purified by passing through a column of $100 \mathrm{~g}$ silica gel. The active fraction was eluted with $200 \mathrm{ml}$ of methanoldichloromethane $1: 19(\mathrm{v} / \mathrm{v})$ and $240 \mathrm{mg}$ of crude active fractions were obtained after concentration under reduced pressure. The crude fractions were further fractionated into two active components by the CAPCELL PAK C18 column $(30 \mathrm{~mm} \times 250 \mathrm{~mm})$ chromatography by developing with a linear gradient of acetonitrile from 50 to $90 \%$ in water at a speed of $9 \mathrm{ml}$ per minute. After 30 minutes from the beginning of the elution, the fractions were collected at 1 minute interval and the bioactive Fractions 1 (fraction 36 to 38 ) and 2 (fractions 45 to 52) were collected. From the Fraction $2,70 \mathrm{mg}$ of yellow needle crystals were obtained after recrystallization from $n$-hexane. The melting point was $130 \sim 132^{\circ} \mathrm{C}$. From the physico-chemical prop- 
Fig. 1. Purification procedure of cochlioquinone A and stemphone.

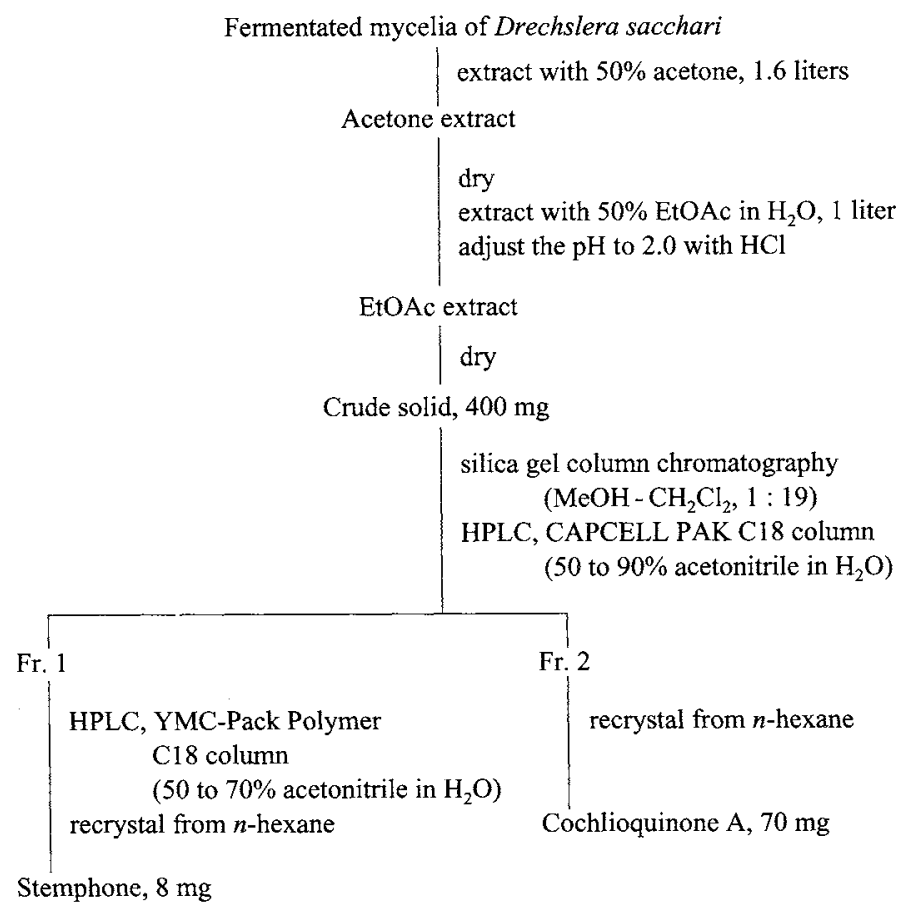

Fig. 2. Chemical structures of cochlioquinone and stemphone.

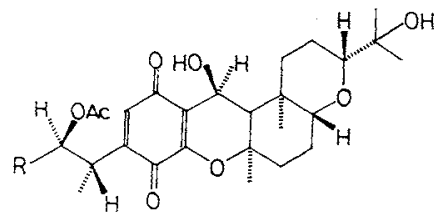<smiles>[R]C(C)CCC(=O)OCOCC</smiles>

$\mathrm{R}=\underset{\stackrel{\mathrm{I}}{\mathrm{C}} \mathrm{H}_{3}}{\mathrm{C}} \mathrm{CHCH}_{3}$ : Stemphone

erties like mass spectrum, ${ }^{1} \mathrm{H}$ and ${ }^{13} \mathrm{C}$ NMR spectra, the crystals were identified as cochlioquinone $A^{5)}$ (Fig. 2). On the other hand, from the Fraction $1,8 \mathrm{mg}$ of yellow needle crystals were obtained after HPLC on YMC-Pack Polymer C18 column chromatography and recrystallization from $n$-hexane. From the physico-chemical properties including melting point $\left(160 \sim 162^{\circ} \mathrm{C}\right)$, the mass spectrum and ${ }^{1} \mathrm{H}$ and ${ }^{13} \mathrm{C}$ NMR spectra, the crystals were identified as stemphone ${ }^{6)}$ (Fig. 2).

Cochlioquinone $\mathrm{A}$ and stemphone showed $\mathrm{IC}_{50}$ values for diacylglycerol kinase from bovine thymus at 2.3 and $3.3 \mu \mathrm{M}$, respectively under the condition of no additional ATP. However, they showed no inhibitory activity against phospholipase $\mathrm{C}$ from bovine brain. Only one compound R59022 has been shown to be an inhibitor of diacylglycerol kinase ${ }^{3)}$ so far, however, a detailed report on its activity has not been described. In addition, although cochlioquinone $\mathrm{A}$ and stemphone were reported to show antimicrobial activity against Bacillus megaterium and toxicity to chick embryo ${ }^{6}$, and to be nematocidal agents ${ }^{7)}$, no report has been published concerning their activities as inhibitors of signal transduction systems. Therefore, cochlioquinone A and stemphone should be useful reagents for the analysis of the detailed mechanism of signal transduction and may be helpful drugs for the diseases caused by disorders of signal transduction systems including cancer. Cochlioquinone A was reported to compete for the specific ivermectin binding site in the membrane preparation from Caenorhabditis elegans ${ }^{7)}$. However, ivermectin did not show inhibitory activity against diacylglycerol kinase (unpublished data).

\section{Acknowledgments}

We are grateful to S. OMURA of the Kitasato Institute for his kind gift of ivermectin. This work is supported in 
part by the Grant-in-Aids for cancer research from the Ministry of Education, Science and Culture of Japan and from the Japan Private School Promotion Foundation.

\section{References}

1) Ogawara, H.; K. Higashi, S. Manita, K. Tanaka, Y. Shimizu \& L. Shufang: An inhibitor for inositolspecific phospholipase C from Actinomudura sp. J. Antibiotics 45: 1365 1366, 1992

2) Ogawara, H.; K. Higashi, S. Manita, M. Hidaka, H. Kato \& T. Takenawa: An inhibitor of inositolphospholipid-specific phospholipase C. Biochim. Biophys. Acta 1117: 289 292, 1993

3) De Chaffoy de Courcelles, D.; P. Roevens \& H. VAN BELLE: R59022, a diacylglycerol kinase inhibitor. J. Biol. Chem. 260: 15762 15770, 1985

4) SaKane, F.; K. Yamada \& H. Kanoh: Different effects of sphingosine, R59022 and anionic amphiphiles on two diacylglycerol kinase isozymes purified from porcine thymus cytosol. FEBS Lett. 255: $409 \sim 413,1989$

5) BARrow, K. D. \& W. S. MurPhy: The structures of alboleersin and luteoleersin; the identity of luteoleersin with cochlioquinone A. J. Chem. Soc. Perkin trans. I 1972: 2837 2839, 1972

6) Scott, P. M. \& J. W. Lawrence: Stemphone, a biologically active yellow pigment produced by Stemphylium sarcinaeforme (Cav.) Wiltshire. Can. J. Microbiol. 14: 1015 1016, 1968

7) Schaeffer, J. M.; E. G. Frazier, A. R. Bergstrom, J. M. Williamson, J. M. Liesch \& M. A. Goetz: Cochlioquinone A, a nematocidal agent which competes for specific $\left[{ }^{3} \mathrm{H}\right]$ ivermectin binding sites. J. Antibiotics 43: $1179 \sim 1182,1990$ 